\title{
CT Fluoroscopy-Guided Drain Placement to Treat Infected Gastric Leakage after Sleeve Gastrectomy: Technical and Clinical Outcome of 31 Procedures
}

\section{CT-fluoroskopisch gesteuerte Drainageneinlage in abdominelle Verhalte bei Nahtinsuffizienz nach Sleeve-Gastrektomien: technische und klinische Resultate von 31 Prozeduren}

Authors

Jens Schwarz' ${ }^{1}$, Frederik Franz Strobl', Philipp M Paprottka', Melvin D’Anastasi' ${ }^{1}$, Fritz W. Spelsberg², Markus Rentsch², Maximilian Reiser ${ }^{1}$, Christoph Gregor Trumm ${ }^{3}$

Affiliations

1 Institute of Clinical Radiology, University Hospitals Munich Campus Grosshadern, Ludwig-Maximilians-University Munich, Germany

2 Institute of General, Visceral, and Transplant Surgery, Ludwig-Maximilians-University Munich, Munich, Germany

3 Institute of Diagnostic and Interventional Neuroradiology Ludwig-Maximilian-University, Munich, Germany

Key words

gastric leakage, drainage, fluoroscopy, sleeve gastrectomy

received 20.01.2019

accepted 07.07.2019

Bibliography

DOI https://doi.org/10.1055/a-0977-3496

Published online: 28.8.2019

Fortschr Röntgenstr 2020; 192: 163-170

(c) Georg Thieme Verlag KG, Stuttgart · New York ISSN 1438-9029

Correspondence

Jens Schwarz

Radiologie, Klinikum der Universität München,

Standort Großhadern, Marchioninistraße 15,

81377 München, Germany

Tel.: ++49/89/440073620

Jens.Schwarz@klinikum-gap.de

\section{ZUSAMMENFASSUNC}

Ziel In dieser Studie wurden die technischen und klinischen Ergebnisse sowie die Sicherheit von CT-fluoroskopisch gesteuerten Drainageneinlagen in entzündete Verhalte bei Nahtinsuffizienz nach Sleeve-Gastrektomien als Teil eines multimodalen Komplikationsmanagements evaluiert.

Material und Methoden In diese retrospektive Studie wurden alle Patienten eingeschlossen, die zwischen 2007 und 2014 in unserer Abteilung eine CT-fluoroskopisch gesteuerte Drainageneinlage in entzündete Verhalte nach Sleeve-
Gastrektomien erhalten haben. Alle Interventionen wurden auf einem 16- oder 128-Zeilen-CT unter intermittierender Fluoroskopie (15-25 mAs, $120 \mathrm{kV}$ ) durchgeführt. Technischer und klinischer Erfolg, die Patientenstrahlendosis (DLP), die Komplikationsrate und ergänzende Therapien wurden analysiert.

Ergebnisse 14 Patienten (Altersdurchschnitt 43,8 \pm 11,3 Jahre, BMI 52,9 $\pm 13,5$, 7 Frauen) wurden eingeschlossen, die insgesamt 31 CT-fluoroskopisch gesteuerte Drainagen erhalten haben. 30 der 31 Interventionen (96,8\%) waren technisch erfolgreich. Sieben Patienten erhielten mehr als eine Intervention aufgrund einer Drainageobstruktion, sekundärer Dislokationen oder als Verlaufstherapie. Peri- und postinterventionell traten keine interventionsbedingten Komplikationen auf. Bei allen Patienten fielen die laborchemischen Entzündungsparameter innerhalb von Tagen nach der Intervention. Das durchschnittliche gesamte Dosislängenprodukt einer Intervention lag bei $1561 \pm 1035 \mathrm{mGy}^{*} \mathrm{~cm}$.

Schlussfolgerung CT-fluoroskopisch gesteuerte Drainageneinlagen sind sichere, minimalinvasive und komplikationsarme Interventionen, um infizierte Verhalte nach Nahtinsuffizienzen bei Sleeve-Gastrektomien zu therapieren. Wir gehen davon aus, dass durch diese Interventionen komplexe Revisionsoperationen bei Hochrisikopatienten vermieden werden können.

\section{Kernaussagen:}

- CT-fluoroskopisch gesteuerte Drainageneinlagen bei adipösen, oft multimorbiden Patienten sind eine technisch gut durchführbare Intervention.

- Eine multidisziplinäre Behandlung (CT-Intervention, Endoskopie und Chirurgie) ist notwendig, um Nahtinsuffizienzen nach bariatrischer Chirurgie erfolgreich zu therapieren.

- Hochrisiko-Revisionsoperationen könnten in vielen Fällen durch CT-gesteuerte Drainageneinlagen verhindert werden. 


\section{ABSTRACT}

Purpose To observe the technical and clinical outcome as well as safety of CT fluoroscopy-guided drain placement in the multimodal clinical complication management of superinfected gastric leakage after sleeve gastrectomy.

Materials and Methods All consecutive patients who underwent CT fluoroscopy-guided drain placement to treat superinfected postoperative leakage after sleeve gastrectomy in our department between 2007 and 2014 were included in this retrospective study. All interventions were performed on a 16- or 128-row CT scanner under intermittent CT fluoroscopy guidance (15-25 mAs, $120 \mathrm{kV})$. The technical and clinical success rates as well as complications, additional therapies and patient radiation dose were analyzed.

Results 14 patients (mean age: $43.8 \pm 11.3$ years, mean BMl: $52.9 \pm 13.5,7$ women) who underwent a total of 31 CT fluoroscopy-guided drain placement procedures were included. 30 of 31 interventions (96.8\%) were technically successful. 7 patients underwent more than one intervention due to drain obstruction or secondary dislocation or as further treatment. During and after the intervention no procedure-associated complications occurred. In all patients, inflammation parameters decreased within days after the CT-guided inter- vention. The total interventional dose length product (DLP) was $1561 \pm 1035 \mathrm{mGy}^{*} \mathrm{~cm}$.

Conclusion CT fluoroscopy-guided drain placement has been shown to be a safe minimally invasive procedure that rarely leads to complications for treating superinfected gastric leakage occurring after sleeve gastrectomy. We assume that operative revisions in a high-risk patient group can be avoided using this procedure.

\section{Key Points:}

- CT fluoroscopy-guided drain placement in obese - often medically highly complex - patients is a technically feasible procedure.

- Multimodal treatment (CT intervention, endoscopy and surgery) is required to successfully treat gastric leakage after bariatric surgery.

- High-risk surgery might be avoided by the CT-guided drain placement.

\section{Citation Format}

- Schwarz J, Strobl FF, Paprottka PM et al. CT FluoroscopyGuided Drain Placement to Treat Infected Gastric Leakage after Sleeve Gastrectomy: Technical and Clinical Outcome of 31 Procedures. Fortschr Röntgenstr 2020; 192: 163170

\section{Introduction}

Over the last decades, excessive weight and obesity have become a major global health and economic problem. Between 1980 and 2014, the prevalence of obesity in Western countries has nearly doubled [1-4]. Correspondingly, from 2005 to 2014 the number of bariatric operations increased fourfold, with $60.8 \%$ of these having been sleeve gastrectomy procedures [5]. One of the most dreaded complications of this operation is a staple line leak with consecutive local or general infection due to the outflow of gastric contents [6]. Patients who undergo sleeve gastrectomy are at high-risk for developing postoperative complications due to their severe obesity and other comorbidities [7, 8].

However, there are a number of options available to treat leakage and attempt to avoid a re-operation.

In order to close the internal site of the insufficient staple line, endoscopic stent implantation is often performed [9, 10]. Another option is placement of an endoscopic clip, which is also a safe method of closing the leak via an endoluminal approach $[11,12]$. Moreover, a combined endoscopic covered stent and double pigtail stent placement across the leakage has been demonstrated to be a valid, curative, safe and minimally invasive treatment approach [11, 12].

In addition, image-guided drain placement can be another promising minimally invasive treatment modality $[13,14]$. Percutaneous drain placement can be performed under ultrasound or $\mathrm{CT}$ guidance. To enable healing of the leak, sufficient drainage is required [15]. Reoperation should only be considered if all of these procedures, alone or in combination, are not feasible.
Kelogrigoris et al. evaluated the success and complication rate of a CT-guided approach in obese patients [16]. In their paper Corona et al. [17] report about the noninvasive management of gastric leaks in 16 patients, 12 of whom were treated with percutaneous drainage.

Several studies have shown that CT interventions in obese patients are more challenging for the physician, assistant staff and patient. Additional equipment for transportation, monitoring and nursing is needed. Comorbidities like hypertension, sleep apnea and diabetes need to be observed [20-22].

The aim of this study was to observe the technical and clinical outcome as well as complications of low milliampere CT fluoroscopy-guided drain placement in the clinical complication management of gastric leakage after sleeve gastrectomy.

\section{Materials and Methods}

\section{Patients}

A retrospective single-center clinical analysis was performed. This included all consecutive patients who underwent low milliampere CT fluoroscopy-guided drain placement in our department due to staple line leakage after bariatric surgery between 2007 and 2014. Patients were included if the aim was to drain an abscess due to suture leakage after gastric sleeve operation with a therapeutic intention. In the retrospective analysis, the score of Gnannt et al. was used to distinguish infected from non-infected abdominal fluid collections (diabetes, CRP value, gas entrapment, CT attenuation) [23]. Scores between 3 and 10 indicated a high prob- 
ability of an infected fluid collection. All of our patients received accompanying broad-spectrum antibiotic therapy in addition to the interventions. The aspirated fluid was microbiologically analyzed and an antibiogram for specific antibiotic therapy was obtained. In all cases previous examinations (including CT, MRI or fluoroscopic esophageal swallow examinations with water-soluble contrast media) confirmed extravasation due to a leak. Indications for drainage procedures were discussed by a multi-disciplinary team of surgeons, endoscopic experts and interventional radiologists prior to the intervention. Previous and subsequent treatments (e.g. stent placement $\left(\mathrm{CHOOSTENT}^{\circledR}\right)$, OTSC ${ }^{\circledR}$ Clip placement, re-operation, CT-guided drain placement) were also considered and evaluated in this analysis. In the study period no implantation of double pigtail endoscopic stents was performed. Patients received total parenteral nutrition for at least three to five postinterventional days.

This study was performed in compliance with the regulations of the local institutional review board. The principles of the Declaration of Helsinki were followed. This retrospective study was approved by our local ethics committee (registration number 17-410). The requirement for informed consent was waived because of the retrospective use of patient data.

\section{Procedures}

For CT guidance, either a 16-row MDCT (Somatom ${ }^{\text {TM }}$ Sensation 16, Siemens Healthcare, Forchheim, Germany) (parameters: $120 \mathrm{kV}, 15$ to $25 \mathrm{~mA}, 12 \times 0.75 \mathrm{~mm}$ collimation, 3-mm slices) or a 128-row MDCT (Somatom ${ }^{\mathrm{TM}} \mathrm{AS}+$ or Edge, Siemens Healthcare) with CT fluoroscopy (CARE Vision CT, Siemens Healthcare) was used. CT fluoroscopy was performed with angular beam modulation (HandCare ${ }^{\mathrm{TM}}$, Siemens Healthcare), i. e., the X-ray beam was turned off within a $120^{\circ}$ angle sector above the patient to decrease radiation exposure to the interventional radiologist and patient.

The best approach for drain placement was determined after evaluation of an initial planning CT scan. For this scan and the post-interventional control scan, an online dose modulation system (CareDOSE 4D, Siemens Medical Solutions) was used, adapting the tube current to the patients' anatomy within the range of $80-120 \mathrm{kV}$ and $100-200 \mathrm{mAs}$. Depending on the location of the leak, surrounding anatomical structures and previous examinations, either a biphasic contrast-enhanced CT scan with an arterial and portal venous phase or an unenhanced CT scan, was performed for drain placement planning. The drain type and size were selected by the interventional radiologist according to the size and expected consistency of the fluid collection.

After skin disinfection, application of local anesthesia and sterile draping, the calculated entry points were marked with a 20-gauge needle under CT fluoroscopy guidance. The applied insertion techniques of a single-lumen drainage catheter were either the Seldinger or the trocar technique, depending on the preferences of the radiologist [24].

After drain placement under CT fluoroscopy, control aspiration was performed to ensure correct placement of the drain. Five to ten minutes after drain placement, an unenhanced control CT scan was acquired to examine the abdomen regarding possible complications, such as bleeding or organ perforation ( $\triangleright$ Fig. 1). The duration of the whole procedure was determined as the time interval between the pre-interventional planning $\mathrm{CT}$ and the last control CT scan.

\section{Technical and clinical outcome}

Technical success of the interventions was achieved if drain placement and consecutive aspiration through the inserted drain were possible [25]. Clinical success was considered to be achieved if the criteria of Lee et al. [26] were fulfilled within 10 days. These criteria were: afebrile patient and a reduction of leukocyte count and decreased catheter drainage to less than 10-15 ml/day. Additionally, the development of the infection parameter serum C-reactive protein (CRP) was observed. The parameters were obtained on the intervention day and 10 days after. In the long term, patients were observed for at least one year for recurrence using the patient charts.

In cases of a multimodal therapeutic approach, the chronology and all therapeutic interventions regarding the leakage were recorded.

\section{Radiation dose}

For each intervention the dose-length product (DLP) was calculated and reported. Therefore, the DLP of the pre-interventional planning $\mathrm{CT}$, the sum of all intra-interventional $\mathrm{CT}$ fluoroscopic acquisitions and the post-interventional control CT were recorded.

\section{Complications}

To assess peri-interventional complications, an interventional radiologist with more than five years of interventional experience examined each CT scan and all intra-interventional CT fluoroscopy acquisitions. For the evaluation of complications regarding the intervention, patient charts for at least one year after the intervention were reviewed. Complications were classified according to the CIRSE Classification System [27].

\section{Statistical analysis}

For data collection and statistical analysis, the software SPSS Version 17.0 (SPSS Inc., Chicago, IL, USA) was used. For normal distribution parameters, a two-sided t-test was used to compare parameters.

\section{Results}

\section{Patient characteristics ( $\triangleright$ Table 1)}

In total, 14 patients ( 7 female, 7 male) with an infected fluid collection (Gnannt-Score between 3 and 10) due to leakage of a gastric sleeve staple line underwent a total of 31 percutaneous CT fluoroscopy-guided drain insertions. The mean age at the time of the intervention was $43.8 \pm 11.3$ years (range: $25-64)$. The mean body-mass index (BMI) was $52.9 \pm 13.5 \mathrm{~kg} / \mathrm{m}^{2}(39.8-$ 82). The staple line leakage was diagnosed $8.45 \pm 3.39$ days after the operation. 

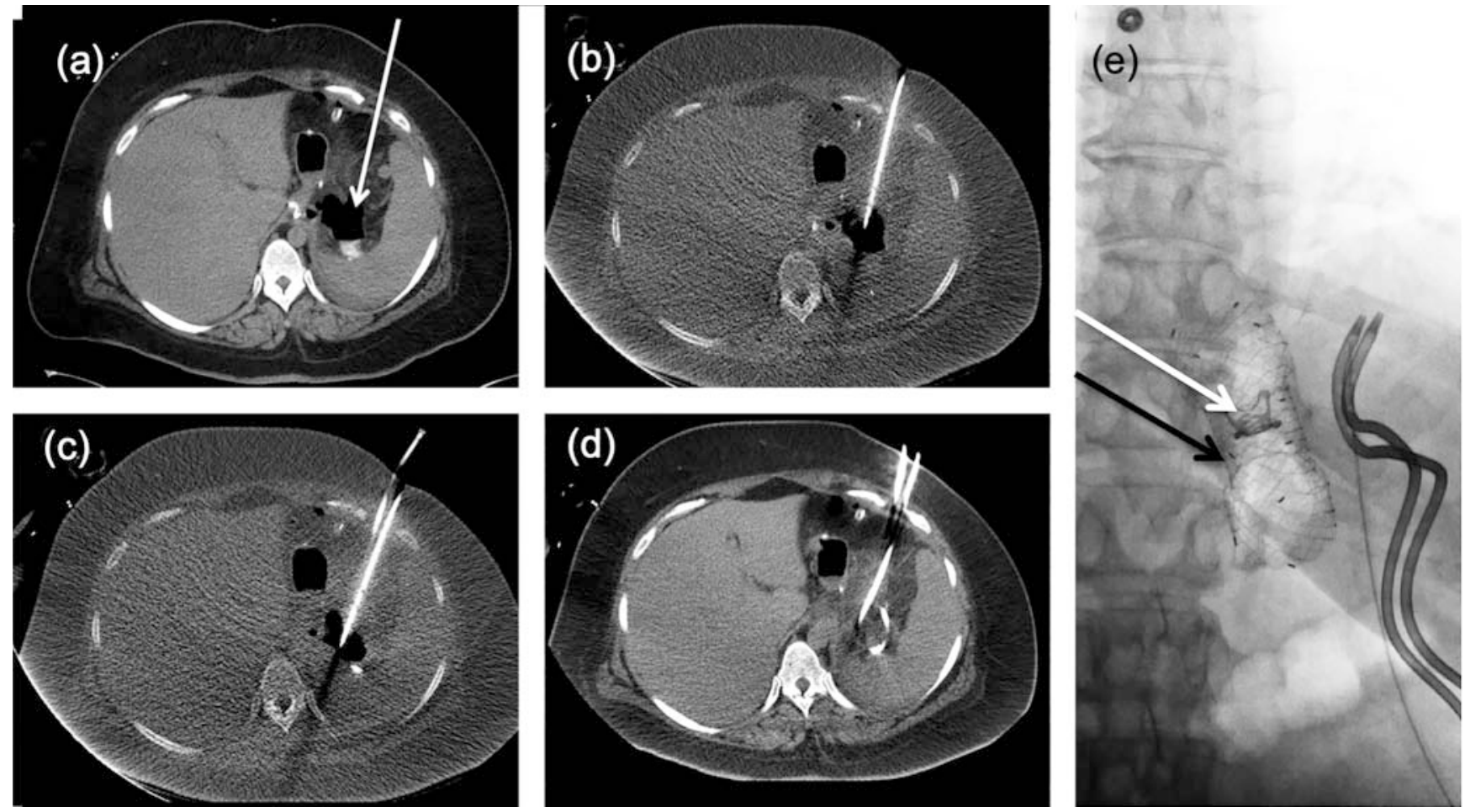

- Fig. 1 CT images of a 37-year-old woman (no. 11) with staple line leakage after sleeve gastrectomy. a Non-enhanced pre-interventional planning CT. Sleeve stomach and extraluminal air-fluid collection (arrow). b Placement of the first 10 French pigtail drain into the collection. $\mathbf{c}$ Placement of a second 10 French pigtail drain, due to the abscess size with gas entrapment. $\mathbf{d}$ Non-enhanced post-interventional control scan. e X-ray image showing an implanted OTSC (white arrow), CHOOSTENT (black arrow) and the two previously inserted abdominal drains.

- Abb.1 CT-Bilder einer 37-jährigen Patientin (Nr. 11) mit Nahtinsuffizienz nach Sleeve-Gastrektomie. a Natives Planungs-CT. Sleeve-Magen mit extraluminalem Verhalt mit Lufteinschlüssen (Pfeil). b Einlage der ersten 10 French Pigtail-Drainage. $\mathbf{c}$ Einlage einer zweiten 10 French PigtailDrainage, aufgrund der Abszessgröße mit Lufteinschlüssen. $\mathbf{d}$ Natives postinterventionelles Kontroll-CT. e Röntgenbild mit Darstellung eines implantierten OTSC (weißer Pfeil), CHOOSTENT (schwarzer Pfeil) und zweier zuvor eingelegter abdomineller Drainagen.

\section{Implementation into clinical complication management}

As depicted in $>$ Table $\mathbf{1}$, drain placement was one procedure within a multimodal therapeutic approach, including other interventions in most cases. In four cases the leakage could be treated by CTF-guided drain placement only. In the other cases an additional endoscopic approach by stent $(n=5)$ and/or OTSC clips $(n=6)$ prior to the CT-guided drain insertion had to be carried out.

\section{Intervention characteristics ( $\triangleright$ Table 2)}

In total, 31 interventions were performed. Single-lumen pigtail drains (8-14 French) (Flexima ${ }^{\odot}$, Boston Scientific, Ratingen, Germany) were selected depending on lesion-size and expected fluid viscosity. In six cases two drains where implanted during one intervention.

The mean calculated DLP was $1561 \pm 1035 \mathrm{mGy}^{*} \mathrm{~cm}$, including the planning and control CT scan $\left(1336 \pm 1008 \mathrm{mGy}^{*} \mathrm{~cm}\right)$ and the fluoroscopic intra-interventional CT images (139 $\left.\pm 219 \mathrm{mGy}{ }^{*} \mathrm{~cm}\right)$.

\section{Outcome and complications}

30 of 31 interventions (96.8\%) were technically successful. In one case, it was not possible to insert a drain due to an abscess $(2 \mathrm{~cm}$ diameter) next to the gastric cardia which was considered too small. The intervention had already been started with needle puncture of the abscess but was terminated because aspiration was not feasible and it was not possible to implant the drain using the Seldinger technique. This procedure was classified as grade 3 according to Filippiadis et al. [27]. The abscess with a diameter of $2 \mathrm{~cm}$ was not an exclusion criterion for the intervention but rather an individual multidisciplinary decision. Seven patients could be treated with one drain placement. During the further clinical course, the other patients needed more than one drain placement. The reasons were the need for further therapy over a longer period, the recurrence of a fluid collection, drain obstruction and accidental dislocation. During a time period of up to 1.5 years, two patients received long-term drainage therapy with six and seven interventions, respectively. Drains were removed if a dislocation was obvious on ultrasound or CT or if there was no fluid output for at least one day.

25 of 30 technically successful interventions (83.3\%) fulfilled the criteria of Lee et al. [26] and led to a significant reduction of the infection parameters during the following ten days ( $>$ Fig. 2). There was a significant difference between the parameters before and 10 days after the intervention (CRP $p=0.001$, leukocytes $p=0.026)$. 
- Table 1 Patient characteristics.

- Tab. 1 Patientenspezifische Daten.

\begin{tabular}{|c|c|c|c|c|c|c|c|c|c|c|}
\hline \multirow[t]{2}{*}{ no } & \multirow[t]{2}{*}{ gender } & \multirow[t]{2}{*}{ age } & \multirow[t]{2}{*}{ BMI } & \multirow[t]{2}{*}{ comorbidities } & \multicolumn{3}{|c|}{ prior to the intervention } & \multirow{2}{*}{$\begin{array}{l}\text { gnannt- } \\
\text { Score }\end{array}$} & \multirow{2}{*}{$\begin{array}{l}\text { no. of CT-guided } \\
\text { drain placement } \\
\text { procedures } \\
\text { (count) }\end{array}$} & \multirow{2}{*}{$\begin{array}{l}\text { dwell time } \\
\text { (days) }\end{array}$} \\
\hline & & & & & CHOOSTENT & OTSC & re-operation & & & \\
\hline 1 & $f$ & 31 & 43 & - & - & $x$ & $x$ & 5 & 1 & (6) \\
\hline 2 & $\mathrm{~m}$ & 43 & 55 & OSA & - & - & - & 6 & 3 & $(1 / 1 / 6)$ \\
\hline 3 & $f$ & 44 & 54 & HT, DM2 & - & - & $X$ & 8 & 1 & (7) \\
\hline 4 & $\mathrm{~m}$ & 28 & & -- & $X$ & $X$ & - & 6 & 2 & $(2 / 7)$ \\
\hline 5 & $f$ & 43 & 41 & $\mathrm{aHT}$ & $x$ & $x$ & & 6 & 6 & $\begin{array}{l}(8 / 13 / 18 / 13 / \\
5 / 21)\end{array}$ \\
\hline 6 & $\mathrm{~m}$ & 49 & 56 & $\begin{array}{l}\text { DM, aHT, OSA, } \\
\text { HLP }\end{array}$ & - & $X$ & - & 7 & 1 & (7) \\
\hline 7 & $f$ & 47 & 63 & DM2, HLP, OSA, & - & - & - & 5 & 1 & (3) \\
\hline 8 & $\mathrm{~m}$ & 25 & 49 & $\begin{array}{l}\text { DM2, OSA, HLP, } \\
\text { aHT }\end{array}$ & $x$ & - & - & 10 & 7 & $\begin{array}{l}(x / 6 / 4 / 6 / 1 / \\
7 / 2)\end{array}$ \\
\hline 9 & $f$ & 47 & 71 & - & - & - & $x$ & 6 & 3 & $(1 / 4 / 2)$ \\
\hline 10 & $\mathrm{~m}$ & 63 & 48 & aHT, DM2, HLP, & $X$ & - & $X$ & 8 & 1 & (6) \\
\hline 11 & $f$ & 37 & 43 & aHT, HLP & $X$ & $X$ & - & 5 & 1 & (31) \\
\hline 12 & $\mathrm{~m}$ & 64 & 40 & - & - & $x$ & - & 4 & 2 & $(5 / 3)$ \\
\hline 13 & $\mathrm{~m}$ & 48 & 82 & aHT, DM2, & - & - & - & 10 & 1 & (16) \\
\hline 14 & $f$ & 44 & 40 & aHT, OSA, HLP & - & - & - & 5 & 1 & (4) \\
\hline
\end{tabular}

- Table 2 Intervention characteristics.

- Tab. 2 Interventionsspezifische Daten.

\begin{tabular}{|c|c|c|}
\hline variable & \multicolumn{2}{|c|}{ n (percentage) } \\
\hline number of interventions & \multicolumn{2}{|l|}{31} \\
\hline technically successful interventions & \multicolumn{2}{|l|}{$30(96.8 \%)$} \\
\hline complications (grade 3) & \multicolumn{2}{|l|}{$1(3.2 \%)$} \\
\hline general anesthesia during intervention & \multicolumn{2}{|l|}{$6(19.4 \%)$} \\
\hline clinical success [24] & \multicolumn{2}{|l|}{$25(83.3 \%)$} \\
\hline & \multicolumn{2}{|l|}{ mean $\pm S D$} \\
\hline time between operation and intervention & \multicolumn{2}{|c|}{$23.83 \pm 22.70$ days } \\
\hline time between operation and CT diagnosis & \multicolumn{2}{|c|}{$8.45 \pm 3.39$ days } \\
\hline duration of intervention & \multicolumn{2}{|c|}{$38.00 \pm 15.83 \mathrm{~min}$} \\
\hline $\begin{array}{l}\text { total calculated DLP } \\
\text { - CT fluoroscopy } \\
\text { - Pre- and post-interventional CT scan }\end{array}$ & \multicolumn{2}{|c|}{$\begin{array}{l}1561 \pm 1035 \mathrm{mGy}^{*} \mathrm{~cm} \\
139 \pm 219 \mathrm{mGy}^{*} \mathrm{~cm} \\
1336 \pm 1008 \mathrm{mGy}^{*} \mathrm{~cm}\end{array}$} \\
\hline size of catheter & $\begin{array}{l}\text { size in French } \\
8 \\
10 \\
12 \\
14 \\
\text { unknown }\end{array}$ & $\begin{array}{l}\mathrm{n} \\
16 \\
8 \\
5 \\
1 \\
4\end{array}$ \\
\hline
\end{tabular}

\section{Post-procedural morbidity and mortality}

No intra-interventional complications were observed. In the 30day post-procedural period, no patient developed complications due to the intervention.

One patient who presented with sepsis had been intubated and mechanically ventilated because of respiratory distress on the day of the intervention but passed away five days after drain placement due to sepsis, circulation instability and multiorgan failure. The patient developed a postoperative abscess in the upper abdomen reaching the mediastinum. Although the drain implanted under CT guidance reached the mediastinum, it was not possible to treat the infection completely. The patient developed subsequent acute respiratory distress syndrome and septic shock, leading to death. This case was not declared a complication according to the CIRSE complication classification system because the $\mathrm{CT}$ intervention was unlikely to be related to the fatal clinical course of the patient.

\section{Discussion}

This study demonstrates that CT fluoroscopy-guided drain placement can be a treatment modality in obese patients with gastric leakage after bariatric surgery. No complications, such as bleeding, pneumothorax, organ perforation or secondary infections, 


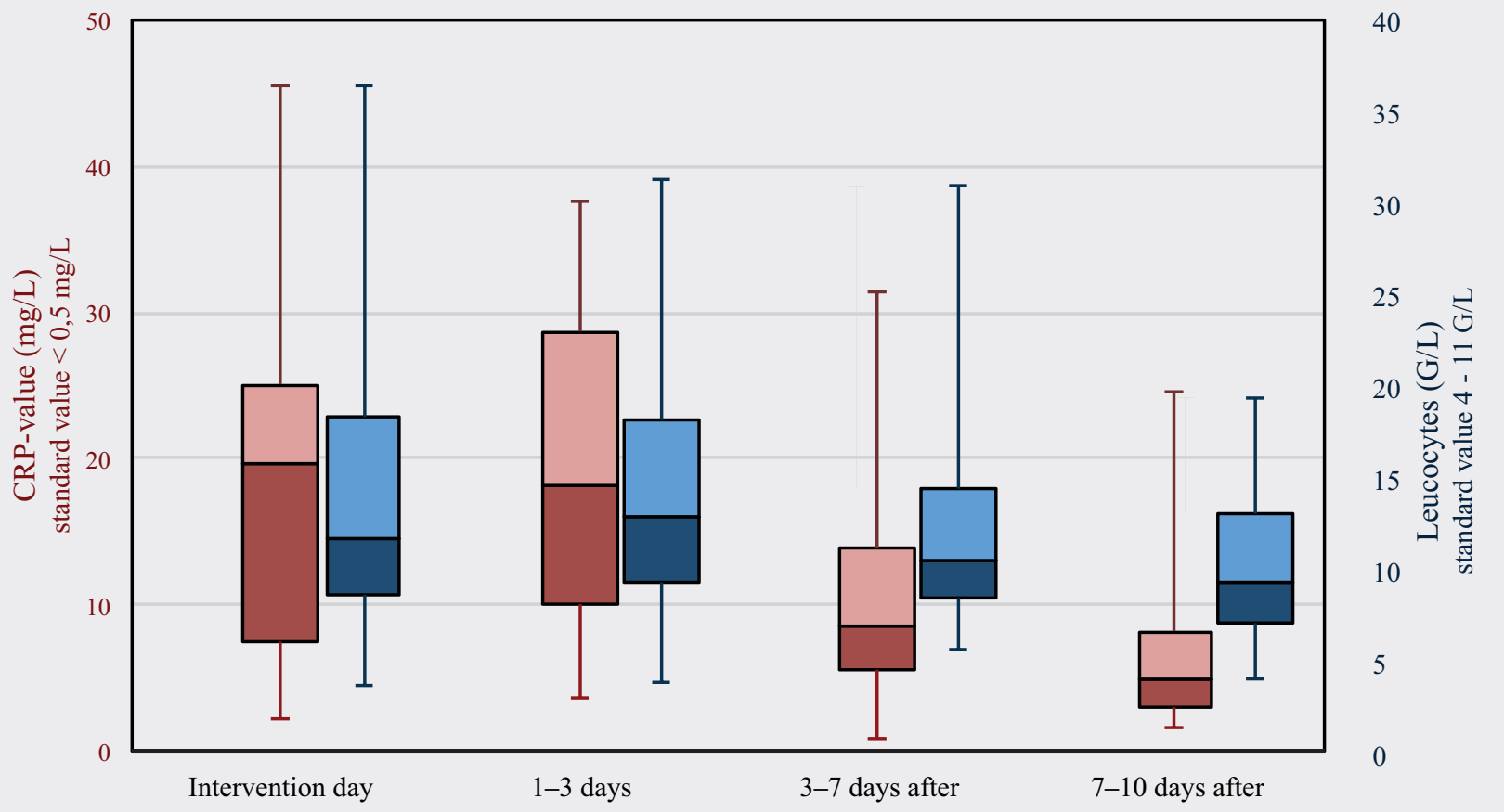

- Fig. 2 Development of CRP (C-reactive protein) and leukocyte count. Box plot of post-interventional CRP values and leukocyte count (range, first quartile, median and third quartile). CRP: p-value: 0.001; leukocyte count: p-value: 0.026 (intervention day vs. 7-10 days after).

- Abb. 2 Verlauf des CRP-Werts (C-reaktives Protein) und der Leukozytenzahl. Box-Plot der postinterventionellen Entwicklung des CRP-Werts und der Leukozytenzahl (Spannweite, erstes Quartil, Median und drittes Quartil). CRP: p-Wert: 0,001; Leukozyten: p-Wert: 0,026 (Interventionstag vs. 7-10 Tage später).

due to drain insertion occurred. The abscess could not be drained only in one case due to its small size ( $2 \mathrm{~cm}$ diameter).

Kelogrigoris et al. evaluated a CT-guided approach with sequential CT guidance for this indication [16]. In comparison to sequential CT guidance, CT fluoroscopy-guided (CTF) interventions can usually be performed faster, safer and with lower patient radiation exposure $[18,19]$. Although both techniques can be used during one intervention, only low-milliampere CTF was used in our interventions.

Our technical success rate was comparable to that of the study by Kelogrigoris et al. (96.8\% vs. $100 \%$ ). Kelogrigoris et al. had a technical success rate of $100 \%$, while our rate was $96.8 \%$. However, clinical success was defined differently in these two studies. Firstly, in our study the criteria of Lee et al. were evaluated (showing a corresponding success rate of $83 \%$ ), whereas Kelogrigoris et al. determined the clinical success as complete closure of the abscess (with a corresponding success rate of $86 \%$ ). Secondly, we considered the clinical implementation of the procedure as part of the antibiotic and anti-inflammatory regime. Four of our patients $(28.6 \%)$ were treated by drain insertion and antibiotic treatment ( $\vee$ Table 1$)$. The other patients underwent an additional re-operation, endoscopic stent implantation or endoscopic clipping prior to CTF-guided drain placement. Although they had a pre-intervention, CTF-guided drain insertion into the infected fluid collection was necessary in the further clinical course.
With the exception of one patient who died five days after the intervention due to sepsis, we could follow up the patients for at least one year after the intervention. All other patients showed complete remission of the fluid collection.

In some cases we had to repeat drain placement within a few days or weeks because the drain had been unintentionally dislodged or had become obstructed. In some other cases the patients were treated over a long time period (up to 1.5 years) with multiple interventions and drain placement until there was complete closure.

The drop in the inflammation parameters shows the success of combined drainage and antibiotic therapy for handling circumscribed superinfected fluid collections adjacent to the leaky staple line. As early as three to seven days after the intervention, a clear decrease in inflammation parameters was registered with a continuous decrease afterwards ( $>$ Fig. 2). Our data underline the clinical success of the multimodal treatment approach.

This study focuses particularly on obese patients (mean BMI: $52.9 \mathrm{~kg} / \mathrm{m}^{2}$ ), a patient category which poses additional challenges such as transportation of the patient and positioning for the CT scan, a higher risk for secondary drain dislocation and superinfection of the fluid collection, numerous comorbidities and a longer stay on the intensive care unit.

Compared to other studies focusing on the insertion of abdominal drains in an unselected patient population, the mean to- 
tal radiation dose was higher in our cases. In comparison to Joemai et al. (681 mGy* cm) [28] or Kloeckner et al. (802 mGy* cm) [29] more than a double DLP $\left(1561 \mathrm{mGy}^{*} \mathrm{~cm}\right)$ was required in total. This difference can be explained by the obesity of our selected patient cohort. A higher mean tube current setting was needed to guarantee sufficient image quality of the preinterventional planning and postinterventional control CT scan. However, the DLP associated with the CT fluoroscopic acquisitions was comparable to the above-mentioned studies (current study: 139 mGy* $\mathrm{cm}$, Joemai: 305 mGy* cm, Kloeckner: $106 \mathrm{mGy}^{*} \mathrm{~cm}$ ). Despite this, it has been reported that the calculated DLP values are often erroneously high in obese patients [30]. Nevertheless, we could show that only a relatively small amount of the radiation dose was attributable to CT fluoroscopy ( $11 \%$ of total). Therefore, the occupational radiation exposure for the interventional radiologist was relatively low.

Generally, it is also possible to drain an abdominal collection under ultrasound guidance. However, of all available imaging modalities, ultrasound is most frequently limited by body habitus $[20,31]$. To the best of our knowledge, there are no studies evaluating abdominal ultrasound-guided drain implantation in very obese patients or after bariatric surgery.

The main limitations of this study are the small number of patients and the retrospective design. This study does not intend to prove the superiority of CTF-guided drain placement in comparison to other treatment modalities, but instead to demonstrate the possibility of performing a standard interventional procedure such as CTF-guided drain placement in a selected cohort of patients characterized by an elevated risk profile. Moreover, to our knowledge, this is the first analysis describing multimodal therapy for infected collections with the focus on CTF-guided drain placement after bariatric surgery in a multi-disciplinary setting.

Corona et al. [17] evaluated a small number of 16 patients with gastric leaks after sleeve gastrectomy. 7 patients (44\%) were successfully treated with percutaneous drainage alone, while 5 patients (31\%) required additional therapy with a covered stent. These results are in line with our findings.

Our data demonstrate that CT fluoroscopy-guided drain placement into a gastric leak is a safe an minimally invasive method to drain infected abdominal collections even in very obese patients. This procedure - if used in a suitable clinical setting - can facilitate the treatment of abdominal abscesses without or in combination with other treatment modalities. We assume that more invasive therapies may thus be avoided. Further studies are required to define the exact role and therapeutic value of CT-guided drain placement for this particular indication.

\section{Conflict of Interest}

The authors declare that they have no conflict of interest.

\section{References}

[1] Hammond RA, Levine R. The economic impact of obesity in the United States. Diabetes, metabolic syndrome and obesity: targets and therapy 2010; 3: 285-295. doi:10.2147/DMSOTT.S7384

[2] Finucane MM, Stevens GA, Cowan M] et al. National, regional, and global trends in body-mass index since 1980: systematic analysis of health examination surveys and epidemiological studies with 960 countryyears and 9.1 million participants. Lancet 2011; 377: 557-567. doi:10.1016/S0140-6736(10)62037-5

[3] Johnson W, Li L, Kuh D et al. How Has the Age-Related Process of Overweight or Obesity Development Changed over Time? Co-ordinated Analyses of Individual Participant Data from Five United Kingdom Birth Cohorts. PLoS medicine 2015; 12: e1001828. doi:10.1371/ journal.pmed.1001828

[4] Organization WH. Global Status Report on Noncommunicable Diseases 2014. World Health Organization. 2015

[5] Debs T, Petrucciani N, Kassir R et al. Trends of bariatric surgery in France during the last 10 years: analysis of 267466 procedures from 20052014. Surgery for obesity and related diseases: official journal of the American Society for Bariatric Surgery 2016. doi:10.1016/ j.soard.2016.05.010

[6] Sarkhosh K, Birch DW, Sharma A et al. Complications associated with laparoscopic sleeve gastrectomy for morbid obesity: a surgeon's guide. Canadian journal of surgery Journal canadien de chirurgie 2013; 56 : 347-352

[7] Winfield RD, Reese S, Bochicchio K et al. Obesity and the Risk for Surgical Site Infection in Abdominal Surgery. The American surgeon 2016; 82: 331-336

[8] Tjeertes EK, Hoeks SE, Beks SB et al. Obesity - a risk factor for postoperative complications in general surgery? BMC anesthesiology 2015; 15: 112. doi:10.1186/s12871-015-0096-7

[9] Slim R, Smayra T, Chakhtoura G et al. Endoscopic stenting of gastric staple line leak following sleeve gastrectomy. Obesity surgery 2013; 23 : 1942-1945. doi:10.1007/s11695-013-1072-2

[10] Simon F, Siciliano I, Gillet A et al. Gastric leak after laparoscopic sleeve gastrectomy: early covered self-expandable stent reduces healing time. Obesity surgery 2013; 23: 687-692. doi:10.1007/s11695-012-0861-3

[11] Shehab HM, Hakky SM, Gawdat KA. An Endoscopic Strategy Combining Mega Stents and Over-The-Scope Clips for the Management of PostBariatric Surgery Leaks and Fistulas (with video). Obesity surgery 2016; 26: 941-948. doi:10.1007/s11695-015-1857-6

[12] Sakran N, Goitein D, Raziel A et al. Gastric leaks after sleeve gastrectomy: a multicenter experience with 2834 patients. Surgical endoscopy 2013; 27: 240-245. doi:10.1007/s00464-012-2426-x

[13] Casella G, Soricelli E, Rizzello M et al. Nonsurgical treatment of staple line leaks after laparoscopic sleeve gastrectomy. Obesity surgery 2009; 19 : 821-826. doi:10.1007/s11695-009-9840-8

[14] Soufron J. Leak or Fistula After Sleeve Gastrectomy: Treatment with Pigtail Drain by the Rendezvous Technique. Obesity surgery 2015; 25: 1979-1980. doi:10.1007/s11695-015-1804-6

[15] Csendes A, Braghetto I, Leon P et al. Management of leaks after laparoscopic sleeve gastrectomy in patients with obesity. Journal of gastrointestinal surgery: official journal of the Society for Surgery of the Alimentary Tract 2010; 14: 1343-1348. doi:10.1007/s11605-010-1249-0

[16] Kelogrigoris M, Sotiropoulou E, Stathopoulos K et al. CT-guided percutaneous drainage of infected collections due to gastric leak after sleeve gastrectomy for morbid obesity: initial experience. Cardiovascular and interventional radiology 2011; 34: 585-589. doi:10.1007/s00270-0109928-5

[17] Corona M, Zini C, Allegritti M et al. Minimally invasive treatment of gastric leak after sleeve gastrectomy. La Radiologia medica 2013; 118 : 962-970. doi:10.1007/s11547-013-0938-7 
[18] Paprottka PM, Helmberger T, Reiser MF et al. Computed tomography guidance: fluoroscopy and more. Der Radiologe 2013; 53: 974-985. doi:10.1007/s00117-012-2460-7

[19] Sarti M, Brehmer WP, Gay SB. Low-dose techniques in CT-guided interventions. Radiographics: a review publication of the Radiological Society of North America, Inc 2012; 32: 1109-1119. doi:10.1148/ rg. 324115072

[20] Aberle D, Charles H, Hodak S et al. Optimizing care for the obese patient in interventional radiology. Diagnostic and interventional radiology 2017. doi:10.5152/dir.2016.16230

[21] Uppot RN. Impact of obesity on radiology. Radiologic clinics of North America 2007; 45: 231-246. doi:10.1016/j.rcl.2007.03.001

[22] Riaz RM, Myers DT, Williams TR. Multidetector CT imaging of bariatric surgical complications: a pictorial review. Abdominal radiology 2016; 41: 174-188. doi:10.1007/s00261-015-0604-8

[23] Gnannt R, Fischer MA, Baechler T et al. Distinguishing infected from noninfected abdominal fluid collections after surgery: an imaging, clinical, and laboratory-based scoring system. Investigative radiology 2015; 50: 17-23. doi:10.1097/rli.0000000000000090

[24] Trumm GC, Hoffmann RT. CT-Guided Biopsy and Drainage. In: Reiser FM, Becker CR, Nikolaou K, et al., Hrsg Multislice CT. Berlin, Heidelberg: Springer Berlin Heidelberg; 2009: 511-534. doi:10.1007/9783-540-33125-4_37
[25] Wallace M], Chin KW, Fletcher TB et al. Quality improvement guidelines for percutaneous drainage/aspiration of abscess and fluid collections. Journal of vascular and interventional radiology: JVIR 2010; 21: 431435. doi:10.1016/j.jvir.2009.12.398

[26] Kaufman JA, Lee MJ. Vascular and Interventional Radiology: The Requisites. 2nd Edition Elsevier - Health Sciences Division; 2013

[27] Filippiadis DK, Binkert C, Pellerin O et al. Cirse Quality Assurance Document and Standards for Classification of Complications: The Cirse Classification System. Cardiovascular and interventional radiology 2017; 40: 1141-1146. doi:10.1007/s00270-017-1703-4

[28] Joemai RMS, Zweers D, Obermann WR et al. Assessment of Patient and Occupational Dose in Established and New Applications of MDCT Fluoroscopy. American Journal of Roentgenology 2009; 192: 881-886. doi:10.2214/ajr.08.1765

[29] Kloeckner R, Santos D, Schneider J et al. Radiation exposure in CT-guided interventions. European journal of radiology 2013; 82: 2253-2257. doi:10.1016/j.ejrad.2013.08.035

[30] Bamberg F, Marcus R, Petersilka M et al. Challenges for computed tomography of overweight patients. Der Radiologe 2011; 51: 366-371. doi:10.1007/s00117-010-2087-5

[31] Uppot RN, Sahani DV, Hahn PF et al. Effect of obesity on image quality: fifteen-year longitudinal study for evaluation of dictated radiology reports. Radiology 2006; 240: 435-439. doi:10.1148/radiol.2402051110 